\title{
Curbing variations in packaging process through Six Sigma way in a large-scale food-processing industry
}

\author{
Darshak A. Desai • Parth Kotadiya • \\ Nikheel Makwana $\cdot$ Sonalinkumar Patel
}

Received: 8 November 2013/Accepted: 23 July 2014/Published online: 27 August 2014

(C) The Author(s) 2014. This article is published with open access at Springerlink.com

\begin{abstract}
Indian industries need overall operational excellence for sustainable profitability and growth in the present age of global competitiveness. Among different quality and productivity improvement techniques, Six Sigma has emerged as one of the most effective breakthrough improvement strategies. Though Indian industries are exploring this improvement methodology to their advantage and reaping the benefits, not much has been presented and published regarding experience of Six Sigma in the food-processing industries. This paper is an effort to exemplify the application of Six Sigma quality improvement drive to one of the large-scale food-processing sectors in India. The paper discusses the phase wiz implementation of define, measure, analyze, improve, and control (DMAIC) on one of the chronic problems, variations in the weight of milk powder pouch. The paper wraps up with the improvements achieved and projected bottom-line gain to the unit by application of Six Sigma methodology.
\end{abstract}

Keywords Six Sigma - Define, measure, analyze, improve, and control (DMAIC) · Large-scale industry . Food-processing industries $\cdot$ Indian industries

\section{Introduction}

Six Sigma is one of the most effective improvement strategies for overall operational excellence. This quantitative approach aims at improving efficiency and effectiveness of

D. A. Desai $(\bowtie) \cdot$ P. Kotadiya $\cdot$ N. Makwana $\cdot$ S. Patel Department of Mechanical Engineering, G. H. Patel College of Engineering and Technology (GCET), Vallabh Vidyanagar, Anand 388 120, Gujarat, India e-mail: darshak301@yahoo.com the organizations. For global competitiveness, Indian industries need overall operational excellence and for that, they are trying many improvement measures, such as, quality circles, TQM, ISO certification, etc. All these techniques are efficient enough of producing the desired results but trouble remain with their implementation and longer time span to realize the benefits. The requirement is for a breakthrough strategy, which can have multidirectional benefits in relatively shorter duration of time, such as, Six Sigma (Desai and Patel 2010). This methodology is having statistical base focusing on removing causes of variations or defects in the product or core business processes. It appears that Six Sigma is not fully explored by Indian industries. Indian industries have experienced periodic impacts of transformation, both, before and after industrial reforms. Initially, the focus has been on large-scale public and private sectors, mainly in core infrastructural production organizations. After globalization and liberalization, quality surfaced as one of the major areas of concern along with productivity (Antony and Desai 2009). From the researches and surveys conducted and published so far, it appears that Six Sigma is not being explored by the developing economies to its full potential and Indian is not an exception in this (Desai and Patel 2009).

This paper is an attempt to illustrate the introduction of Six Sigma as an effective quality improvement drive to one of the large-scale food-processing sectors in India. The paper discusses the phase wiz implementation of define, measure, analyze, improve, and control (DMAIC) on one of the chronic problems, variations in the weight of milk powder pouch. The paper concludes with rate of improvements achieved and projected bottom-line gain to the concern by application of Six Sigma methodology.

The selection of processing unit for this study is justified on the fact that milk and milk products sector is the second 
largest subsector in the food-processing industry next to commodities (pulses and cereals). Indian dairy industry is about $16 \%$ of the Indian food industry with an output value of Rs 1,179 billion (2004-05). India is the largest milk producer in the world (about 100 million MT) and consists of nearly $1 / 5$ th of the world bovine population (Deloitte 2009). Further, (Sharma and Rao 2013) revealed that the DMAIC approach is the best methodology for problem solving tools to improve the manufacturing process capability levels.

\section{Literature review}

\section{An overview on Six Sigma}

Six Sigma has been defined by many experts in numerous ways. In couple of initial definitions Tomkins (1997) defined Six Sigma as a program aimed at the near elimination of defects from every products, process, and transactions. Harry (1998) defined Six Sigma as a strategic initiative to boost profitability, increase market share and improve customer satisfaction through statistical tools that can lead to breakthrough quantum gains in quality.

Six Sigma provides business leaders and executives with the strategy, methods, tools, and techniques to change the culture of organizations (Antony et al. 2005). Six Sigma is a systematic, highly disciplined, customer-centric, and profit-driven organization-wide strategic business improvement initiative that is based on a rigorous process focused and data-driven methodology (Tang et al. 2007). As per Voelkel (2002) the business-oriented definition of Six Sigma states that it blends correct management, financial, and methodological elements to make improvement to process and products in ways that surpass other approaches. As per Shahin (2008) the corporate framework of Six Sigma embodies the five elements of top-level management commitment, training schemes, project team activities, and measurement system and stakeholder involvement. Stakeholders include employees, owners, suppliers, and customers. At the core of the framework is a formalized improvement strategy with the following five steps: define, measure, analyze, improve, and control (DMAIC). The improvement strategy is based on training schemes, project team activities, and measurement systems.

Six Sigma is a holistic approach to achieving near perfection, expressed in terms of no more than 3.4 errors per million opportunities. This near perfection appears to many to be overkill or to some, an impossible ideal. Nonetheless, Six Sigma has been adopted by many leading companies. The benefits are well documented for manufacturing industries and increasingly, in service industries (Wright and Basu 2008). As per Lucas (2002) Six Sigma is a business system with many statistical aspects, and it naturally fits the business systems of most companies. It is an operational system that speeds up improvement by getting the right projects conducted in the right way. As per Snee (2004) Six Sigma is a business improvement approach that seeks to find and eliminate causes of mistakes or defects in business processes by focusing on process outputs that are of critical importance to customers.

Technically, sigma(s) is a statistical measure of the quality consistency for a particular process/product. The technical concept of Six Sigma is to measure current performance and to determine how many sigmas exist that can be measured from the current average until customer dissatisfaction occur. When customer dissatisfaction occurs, a defect results (Eckes 2001). As per Park (2002) Six Sigma implies three things: statistical measurement, management strategy, and quality culture. It tells us how good products, services, and processes really are, through statistical measuring of quality level. Six Sigma is new, emerging, approach to quality assurance and quality management with emphasis on continuous quality improvements. The main goal of this approach is reaching level of quality and reliability that will satisfy and even exceed demands and expectations of today's demanding customer (Pyzdek 1999).

Food-processing sector and quality initiatives

The market size of global food, beverage, and tobacco products was estimated to be US $\$ 4,140.3$ billion in 2005 . The size of the global market is around $\$ 3,660$ bn in 2005 (not considering tobacco industry which constitutes about $11 \%$ ) and estimated to grow to $\$ 4,320$ bn in 2010 with CAGR around $3.35 \%$. Figure 1 illustrates category wiz contribution of global food and beverage sector (Deloitte 2009).

The total size of the Indian food industry is around US $\$ 220$ bn in 2005. Of that, primary processed food is around $\$ 70$ bn and the value added segment is about $\$ 40$ bn. Annual growth rate of the industry is around 9-12\%. The processing levels in India range from $2.2 \%$ in fruits and vegetables to around $35 \%$ in milk production. The market size for the processed foods is expected to increase from US $\$ 110$ billion to US $\$ 330$ billion by $2014-15$ assuming a growth of $10 \%$. Figure 2 shows structure of Indian food-processing industries (Deloitte 2009).

The commercial food-processing industry has a strong link to quality practices. However, the food-processing industry has also been characterized as being conservative and slow to change. Understanding the quality practices in food processing requires an understanding of how the consumer, the nature of food, and the regulatory 


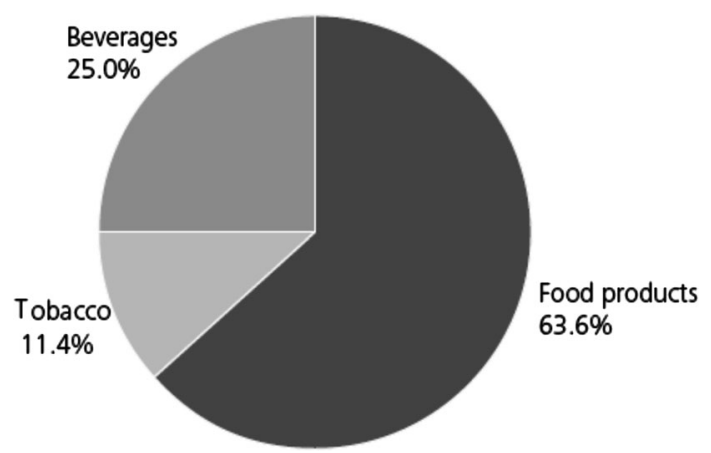

Fig. 1 Global food and beverage sector-category wiz contribution (Deloitte 2009)

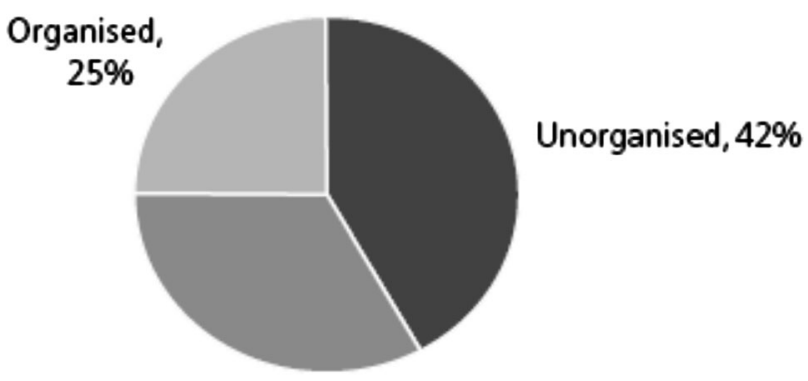

SmallScale, 33\%

Fig. 2 Structure of Indian food-processing industries (Deloitte 2009)

environment interact to affect the industry. Food industry managers must thus consider how to maintain profitability in a shrinking market, while providing increasingly sophisticated customers with high-quality products and efficient service. In attempting to achieve this seemingly impossible objective, firms can pursue two strategic avenues. First, they can focus on ways to improve the operational efficiency of the system. Second, they can take actions to enhance its operational quality (Hung and Sung 2011)

Different from general industry, the food and beverage industry faces its own challenges. Fierce competition, high variable material costs, regulatory requirements, and quality management are just a few examples (Cutler 2007). Successful stories of Lean Six Sigma implementation are common in general industry. Unfortunately, the implementation of Lean Six Sigma in the food industry is still limited. However, in the Lean Six Sigma case studies, they showed the possibilities of continuous quality improvement in the food industry (Kovach and Cho 2011). An article "Better Processes Make Good Eats", elaborates the importance of continuous quality improvement in the food industry. The authors analyzed the specifications of food industry from the customers' expectation to the variations in this manufacturing. A theoretical case study was given out to how to start a Lean Six Sigma case (Kovach and Cho 2011). Six Sigma education institute-Aveta Business published article "Practical Applications in Fast Food", which theoretically elaborated that the idea of Lean Six Sigma is to eliminate wastes and improve process efficiency is a perfect match with fast food industry (Six Sigma Online 2009). In the article written by Cutler (2007) he pointed out that developing a Six Sigma program will benefit a food company substantially and lead to the success in the food and beverage industry. He introduced DMAIC and quality function deployment (QFD) as recommendations for this industry.

In a thesis titled Food Safety and Lean Six Sigma Model (Zhen 2011) demonstrated that Lean Six Sigma tools will contribute to the implementation of the food safety system to minimize risk, improve productivity and quality of products, and reduce unnecessary waste and time.

There are some publications of Six Sigma applications in supply chain of food products. Nabhani and Shokri (2007) explored the possibilities of implementation of a quality initiative system, especially Six Sigma to improve the objectives in supply chain management for a food distribution small- and medium-sized enterprise (SME). They concluded that food distribution SMEs have got the potential to implement the quality initiatives if there is an integrated and collaborative approach in alignment with SC objectives and if there is enough knowledge of the terminology, the principles and the tools in quality initiatives.

Chakrabortty et al. (2013) worked on reducing process variability in one of the renowned food product manufacturers of Bangladesh. They noticed five major types of defects which normally occur. Those are leakage, presence of black particle, leaving bottles without coding, excess/ short materials fill up and cap loose. Alarming to see that the process mean's spread of the products was far away from the mean in both sides. To reduce this spread of the process, the process needs to be improved. They used the Six Sigma approach to reduce process variability. DMAIC model has been used to implement the Six Sigma Philosophy. Five phases of the model have been structured step by step, respectively. Different tools of Total Quality Management, Statistical Quality Control, and Lean Manufacturing concepts likely Quality function deployment, P Control chart, Fish-bone diagram, Analytical Hierarchy Process, Pareto analysis have been used in different phases of the DMAIC model. The process variability have been tried to reduce by identifying the root cause of defects and reducing it.

In a study conducted by Zhang et al. (2012) to review the literature on Lean Six Sigma (LSS) implementation they focused on different perspectives, such as implementation of lean six sigma, focus area, focus industry, focus country, year wise publications, and year wise focus 
area and focus industry. The study reported that focus area of implementation of LSS mainly has been Process improvement. The organization adopted LSS either to improve their processes or modify them to increase efficiency and productivity. But food-processing industries emerged at a very lower position in Six Sigma implementation. However, the industry wiz focus area reported for LSS implementation in food processing was found as process improvement. One of the studies (Nabhani and Shokri 2009) revealed implementation of Lean Six Sigma concepts in a food distribution company. The food distributor in Northeastern England received numerous customer complaints which accounted for $£ 100,000$ on an annual basis. After gaining an understanding of that process with the SIPOC concept and enumeration of the problem areas from the database, they realized that $50 \%$ of the problems were in late delivery of the goods. After establishing a baseline for the performance, the team analyzed the causes of the problem and started investigating solutions to alleviate it. After implementation of the solutions, the number of defects reduced resulting into the increase in sigma of the process from 1.44 to 2.09. They also reported reduction in waiting time and thus organization saved nearly $£ 30,000$ annually.

As reported by Jonathan Chong, Director of Business Development, TBM Consulting Group-Mexico, the DMAIC process using Six Sigma tools can be effectively used in the food and beverage industry and other continuous process manufacturing environments to improve rawmaterial utilization, thereby providing a significant contribution to the bottom line. He further emphasized that often many food and beverage manufacturers collect and archive a mountain of process data but do not analyze them or use them to improve their processes. Usually, the data collected is in an incorrect format or cannot be used because it was collected using inadequate measurement system. By effectively applying the DMAIC process and Six Sigma tools, significant financial benefits, often 1-2\% of annual sales, can be realized from improving raw-material utilization.

Application of Six Sigma is also reported at the backend of food-processing industries, for example, dairy farm. Tylutki and Fox (2002) devised and implemented a quality management programme based on Six Sigma's DMAIC approach to manage the feed costs of a dairy farm.

National Productivity Council, New Delhi has demonstrated productivity, quality, and food safety improvement in a cooperative body in the public sector. As a matter of fact the project has helped Sikkim Dairy in turning around to a profitable venture. The project exemplifies various interventions that can be a good learning experience for dairy industry particularly in the Hilly Region of the India (NPC 2012). Evidences are also there from Asian
Productivity Organization working on the safety and quality of food-processing units. The APO multicounty observational study mission (OSM) on Best Practices and Systems for Food Safety and Quality Applicable to Foodprocessing SMEs was held in Japan, 12-17 November 2012, with 18 participants from 15 member countries (APO 2013).

\section{Research objectives and methodology}

As revealed from the literature survey that application of Six Sigma improvement methodology appears rare among the large-scale food-processing sectors in India. Thus, the basic objective of this study is to implement Six Sigma at one of the leading food-processing units and illustrate the benefits drawn out of the same. The DMAIC methodology was applied to one of the chronic problems having considerable impact on the quality and productivity of the unit in question.

The methodology adopted was case-study-based research. A single well-designed case study can provide a major challenge to a theory and provide a source of new hypotheses and constructs simultaneously (Cooper and Schinddler 2005). The paper discusses one complete implementation case of Six Sigma pilot project. The case study place more emphasis on a full contextual analysis of fewer events or conditions and their interrelations. A case study is an empirical inquiry that investigates a contemporary phenomenon within its real-life context, when the boundaries between phenomenon and context are not clearly evident, and in which multiple sources of evidence are used (Yin 2003). The case-study method allows an investigator to retain the holistic and meaningful characteristics of real-life events. Further, As per Simon (1969), case study is a method of choice when the researcher wants to obtain a wealth of information about the subject.

Following text demonstrates complete phase wiz implementation of DMAIC methodology at a large-scale food-processing unit resulting in improvement in productivity and quality.

\section{Application of Six Sigma}

The company and project objectives

The company in question is one of the leading cooperative sectors of India engaged mainly in milk products. The Six Sigma methodology was applied to the milk powder packaging unit having almost all the variety of the products running on mechanized packaging line. Though the unit was operating on automation, deviations were observed in 
the weight of milk powder packets being produced which resulted into loss of production and revenue. The unit was trying to dilute these rejections, through different trial and errors but not satisfied with the results. The unit executives were appraised regarding the basics of DMAIC methodology and they comprehended that the problem being faced by them needs the systematic treatment involving exact definition of the problem, analysis of facts and figures, detection of the real root causes and then arriving at the appropriate solution. Packaging of dairy products has excellent potential and growth areas. Package has become the competitive tool to reach the consumer. This has opened the sector for introduction of modern technology for processing and packaging. Cost of packaging ranges anywhere from 10 to $64 \%$ of production costs and efforts should be made to reduce these costs through use of manufacturing automation and economies of scale.

Six Sigma is a project-driven approach and by which the organization can achieve the strategic goal through effectively accomplishing projects. Notably, project generation and priority performs the most critical parts while carrying out Six Sigma initiations. The project selection decision, under a resource constraint, is the early stage of implementation for a Six Sigma intervention (Bilgen and Sen 2012).

Six Sigma projects can be defined as the process through which companies are able to reduce defects and improve the quality of business processes (Dedhia 2005). The success of any Six Sigma project depends on a number of factors such as clearly defined objectives, the support and leadership of top management, and a comprehensive training programme (Lucas 2002).

It was then decided to apply Six Sigma methodology to reduce the deviation in the weight of milk powder packet of $1 \mathrm{~kg}$ category. Along with this prime objective, following secondary objective are also considered:

$\checkmark$ Introduction of the Six Sigma DMAIC methodology to the unit.

$\boldsymbol{V}$ Making the unit familiar with DMAIC problem solving technique, so that the same can be applied on other product line.

$\checkmark$ Creating the path for continuous improvement through project-by-project improvements in sigma level in reducing variations in packaging.

The following text elucidates the phase wiz application of DMAIC methodology on the selected problem.

\section{Define phase}

This is one of the most significant phases of DMAIC methodology. This phase helps define the problem in minute details and thus making the way ahead more clear in terms of actions required to be taken.
The project charter in this case includes defining problem statement and drawing CTQ tree. The business case is created keeping strategic objective of the concern in view and that is to increase profitability by attacking on waste reduction in milk powder pouch packing. Since the final outcome of the process is packaging, the entire process mapping in the form of SIPOC is not included here for simplicity.

\section{The problem statement}

The problem statement should be specific and measurable, since it is making foundation for the improvement efforts. The problem statement is fixed as....

"To reduce the variations in the weight of $1 \mathrm{~kg}$ milk powder pouch".

\section{CTQ tree}

This will help to recognize the critical quality requirements of the product. This will also help in identify the opportunities through which a product may fail. Figure 3 shows the CTQ tree of the project in question.

\section{Measure phase}

This is fundamentally a data collection phase wherein present state of affairs data is collected and then current sigma level (baseline sigma) is calculated for the project in question.

\section{Relevant data collection and calculation of current sigma level}

The process of filling up $1 \mathrm{~kg}$ milk pouch was thoroughly observed with a view to examine the deviation pattern, if any. For calculation of baseline sigma level after few trials the data were collected for 25 samples having subgroup size 36. This set of data were tested for normality and found to be satisfactory for further statistical analysis (Fig. 4).

The data then analyzed through statistical control charts (X-bar and $\mathrm{S}$ charts) and $\mathrm{Cp}$ and $\mathrm{Cpk}$ values calculated through statistical analysis software. Based on the same the present sigma level was worked as 3.24. Figure 4 illustrates the same.

Analyze phase

Following tools and techniques were adopted during this investigation phase to uncover the most critical root causes.

1. Open root cause analysis - cause-effect diagram

2. Narrow root cause analysis-multivoting and Pareto charting 
Fig. 3 CTQ tree for $1 \mathrm{~kg}$ milk powder pouch

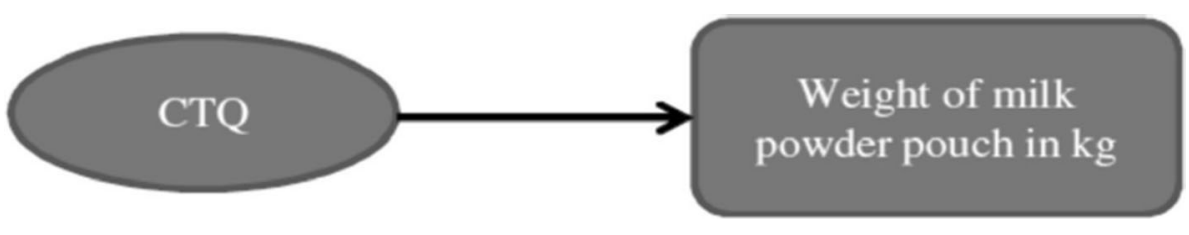

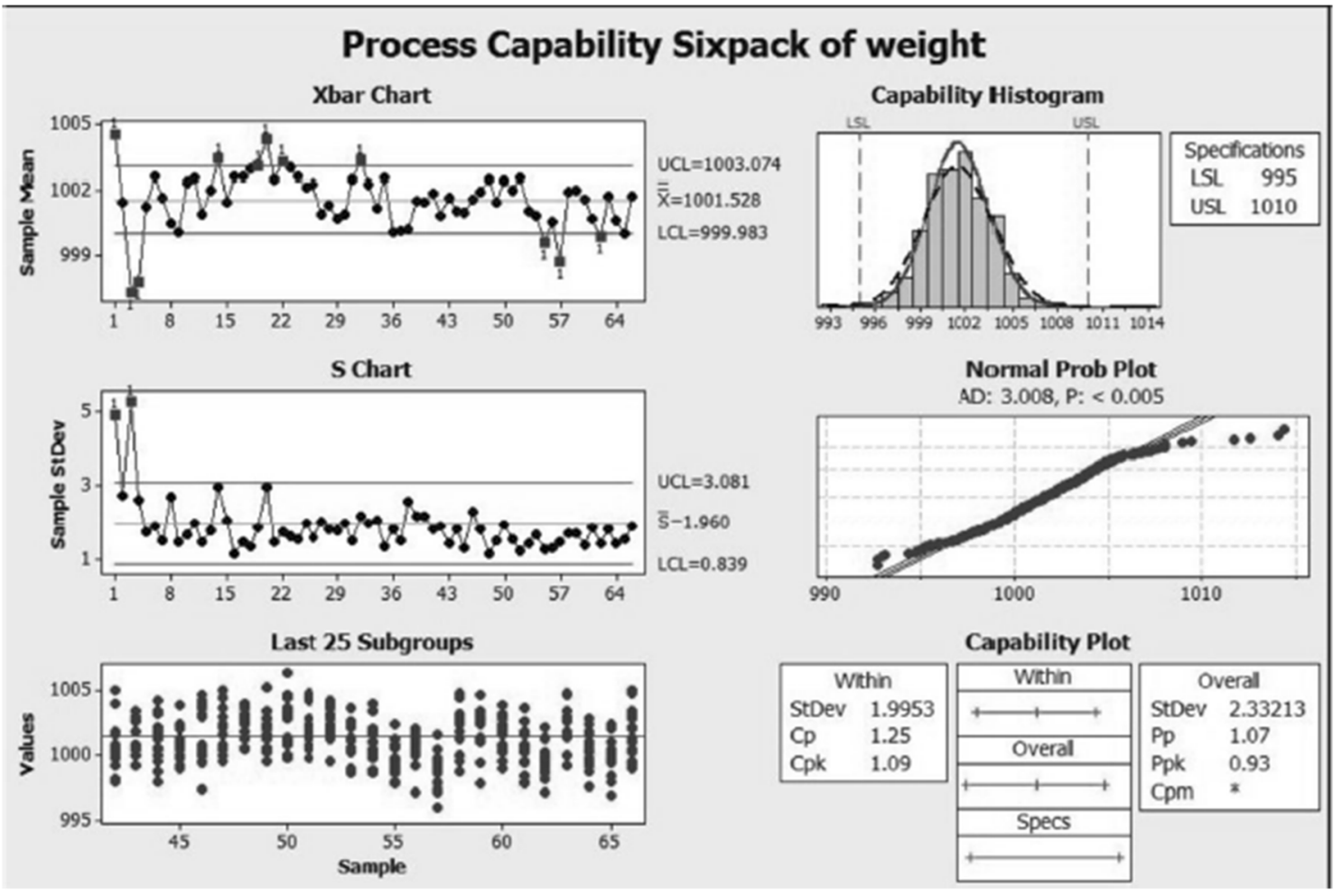

Fig. 4 Test of normality, control charts of present data and calculations of $\mathrm{Cp}$ and $\mathrm{Cpk}$

3. Close root cause analysis-five-why analysis

Root cause analysis—open after rigorous brainstorming, total 13 probable causes were generated for the problem of weight deviation for $1 \mathrm{~kg}$ of milk powder pouch. These probable causes were then categorized as shown in causeeffect diagram in Fig. 5.

Root cause analysis-narrow during this stage of analysis, multivoting was done. Approach to multivoting is subjective. Here, the team members were asked to vote each cause based on their understanding of the most probable to least probable root cause for the problem at hand. The causes were voted by the team on a scale of $1-5$, with 5 as the most probable root cause for the problem at the hand 1 as the least probable cause. Table 1 indicates the multivoting results.

Based on the result of multivoting, the list of the probable root causes was reduced discarding the causes that got average ranking of 2.5 and below. Table 2 shows the final list of causes and Fig. 6 illustrates the Pareto chart of the same.
Root cause analysis-close all the root causes as short listed after multivoting were scrutinized individually through the "five-why" techniques. A list of questioning was prepared for each cause asking why it occurred and then capturing as many answers as possible for each question.

List of some why questions...

- Why wear and tear takes place between augar screw and tube?

- Why powder sticks to screw material?

- Why steel is used as screw material?

- Why there is play between augar screw and tube?

- Why there is considerable deviation in weight of pouch when machine is just started?

So, by asking why questions like stated above "fivewhy" analysis was carried out for each of the following short-listed root cause. The outcome of the same is illustrated in Figs. 7, 8, 9 and 10. 
Fig. 5 Cause-effect diagram

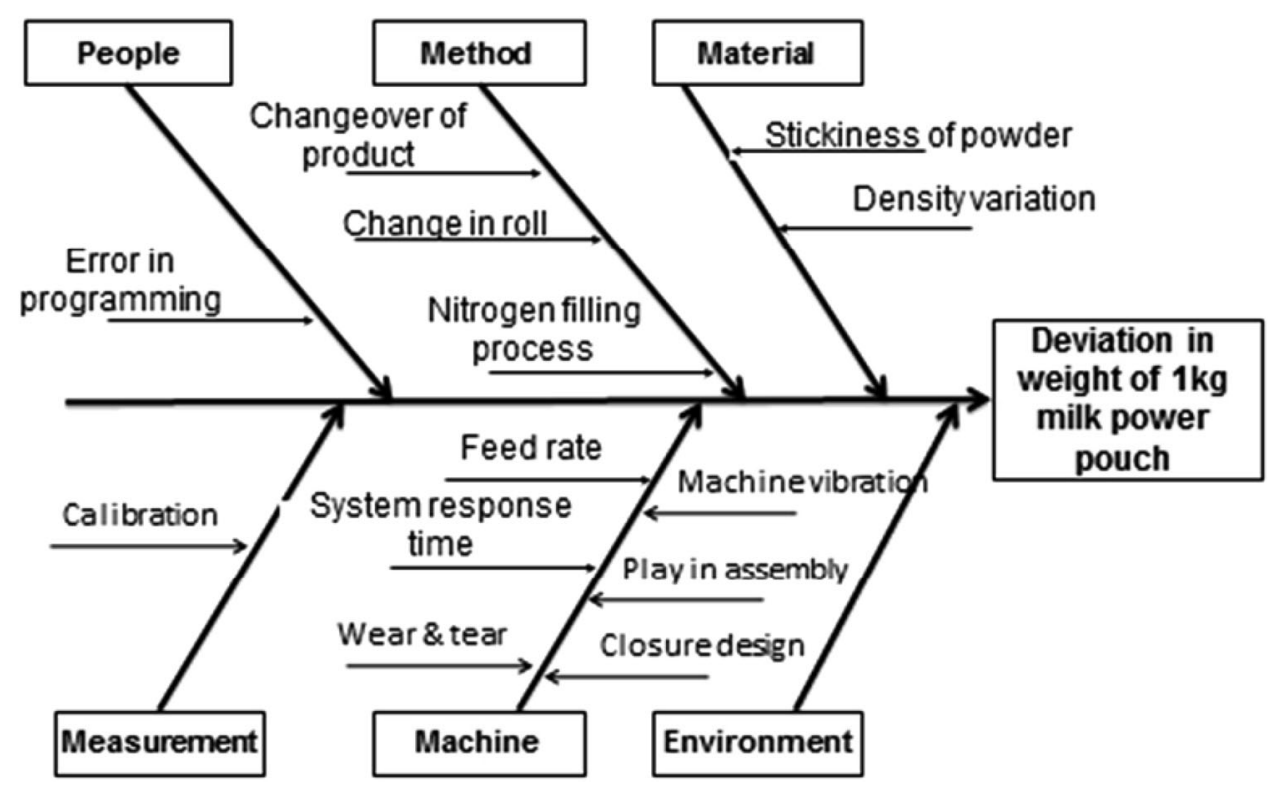

Table 1 Multivoting results

\begin{tabular}{|c|c|c|c|c|c|c|c|c|c|}
\hline \multirow[t]{2}{*}{$\begin{array}{l}\text { Sr. } \\
\text { no. }\end{array}$} & \multirow[t]{2}{*}{ Probable cause } & \multicolumn{7}{|c|}{$\begin{array}{l}\text { Voters (process owners } \\
\text { and project team } \\
\text { members) }\end{array}$} & \multirow[t]{2}{*}{ Avg. } \\
\hline & & A & B & $\mathrm{C}$ & $\mathrm{D}$ & $\mathrm{E}$ & $\mathrm{F}$ & $\mathrm{G}$ & \\
\hline 1 & $\begin{array}{l}\text { Wear and tear of augur } \\
\text { screw and tube }\end{array}$ & 5 & 5 & 4 & 5 & 5 & 5 & 5 & 4.85 \\
\hline 2 & $\begin{array}{l}\text { Weighing machine } \\
\text { calibration }\end{array}$ & 4 & 2 & 3 & 4 & 3 & 5 & 3 & 3.43 \\
\hline 3 & $\begin{array}{l}\text { Vibration in filling } \\
\text { machine }\end{array}$ & 3 & 2 & 2 & 3 & 3 & 4 & 3 & 2.86 \\
\hline 4 & Density variation & 5 & 4 & 4 & 2 & 4 & 4 & 3 & 3.71 \\
\hline 5 & Changeover of product & 2 & 2 & 2 & 2 & 2 & 3 & 3 & 2.86 \\
\hline 6 & Stickiness of powder & 2 & 2 & 2 & 3 & 2 & 5 & 4 & 2.85 \\
\hline 7 & $\begin{array}{l}\text { Closure design and the } \\
\text { end of the screw }\end{array}$ & 2 & 1 & 1 & 4 & 1 & 3 & 2 & 2.00 \\
\hline 8 & System response time & 2 & 1 & 1 & 3 & 4 & 3 & 3 & 2.43 \\
\hline 9 & Error in programming & 2 & 1 & 1 & 1 & 2 & 2 & 2 & 1.57 \\
\hline 10 & Feed rate & 5 & 5 & 5 & 3 & 5 & 3 & 4 & 4.28 \\
\hline 11 & Stirrer design & 5 & 5 & 5 & 4 & 1 & 2 & 4 & 3.71 \\
\hline 12 & Operating condition & 3 & 3 & 3 & 2 & 2 & 1 & 2 & 2.28 \\
\hline
\end{tabular}

$\checkmark$ Wear and tear

$\checkmark$ Stickiness of powder

$\checkmark$ Feed rate

$\checkmark$ Changeover of product

Improve phase

At this phase, the following procedures were adopted.

Setting improvement targets present sigma level for filling process was as worked out during Measure phase. The approved thumb rule of $50 \%$ improvement in the first
Table 2 Final list of causes

\begin{tabular}{lll}
\hline Sr. no. & Probable cause & Avg. ranking \\
\hline 1 & Wear and tear of augur screw and tube & 4.85 \\
2 & Weighing machine calibration & 3.43 \\
3 & Vibration in filling machine & 2.86 \\
4 & Density variation & 3.71 \\
5 & Changeover of product & 2.86 \\
6 & Stickiness of powder & 2.85 \\
7 & Feed rate & 4.28 \\
8 & Stirrer design & 3.71 \\
\hline
\end{tabular}

effort of Six Sigma drive was applied here to set targets which should result from the Improve measures. Accordingly, based on the rejection data (25 items rejected out of 37,500 total items produced) targets worked out for $50 \%$ improvements. Thus, the total numbers of items allowed to be rejected after implementing pilot Six Sigma project would be 12 . This is equivalent to 4.53 Sigma level.

Designing improvement measures based on the root causes and the answers emerged from the five-why techniques, the following improvement measures were worked out.

- Alignment between augar screw and tube assembly should be checked every time when product changeover occurs.

- Air conditioning system must be able to meet the condition requirement of air in the room.

- Calibration frequency of weighing machine should be at least twice per month.

- Design of feedback loop of control system such that system response time reduced to minimum possible level. 
Fig. 6 Pareto chart of final causes

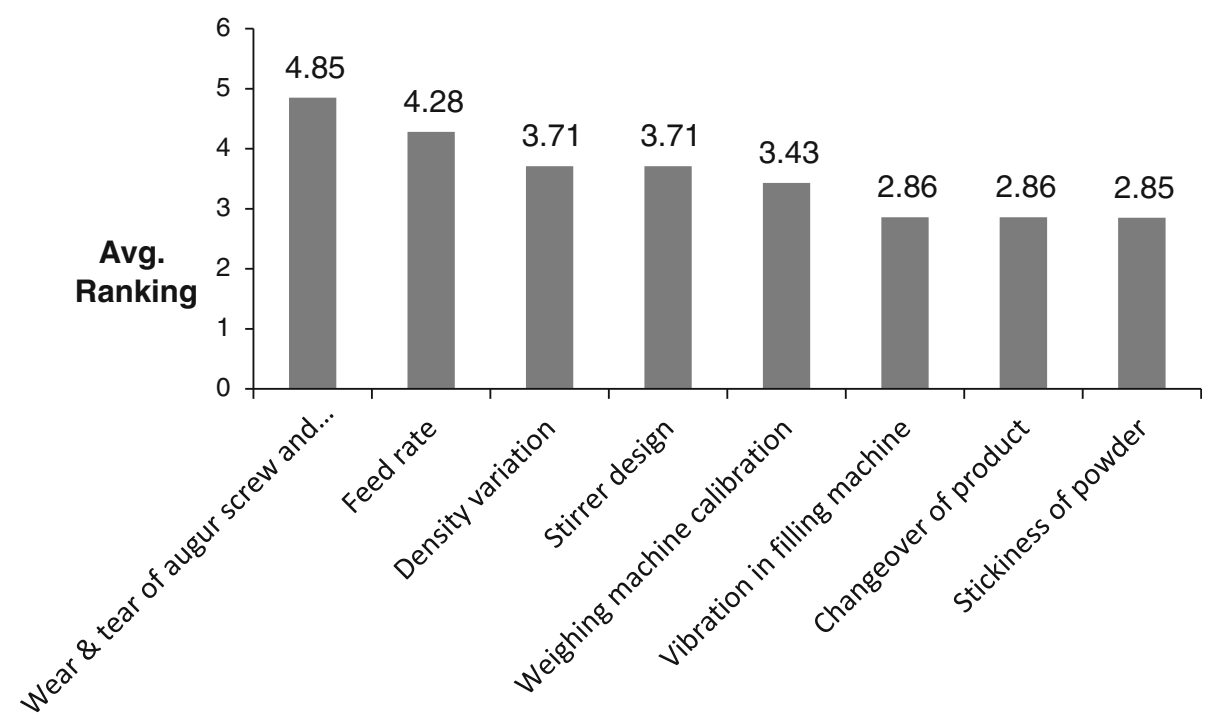

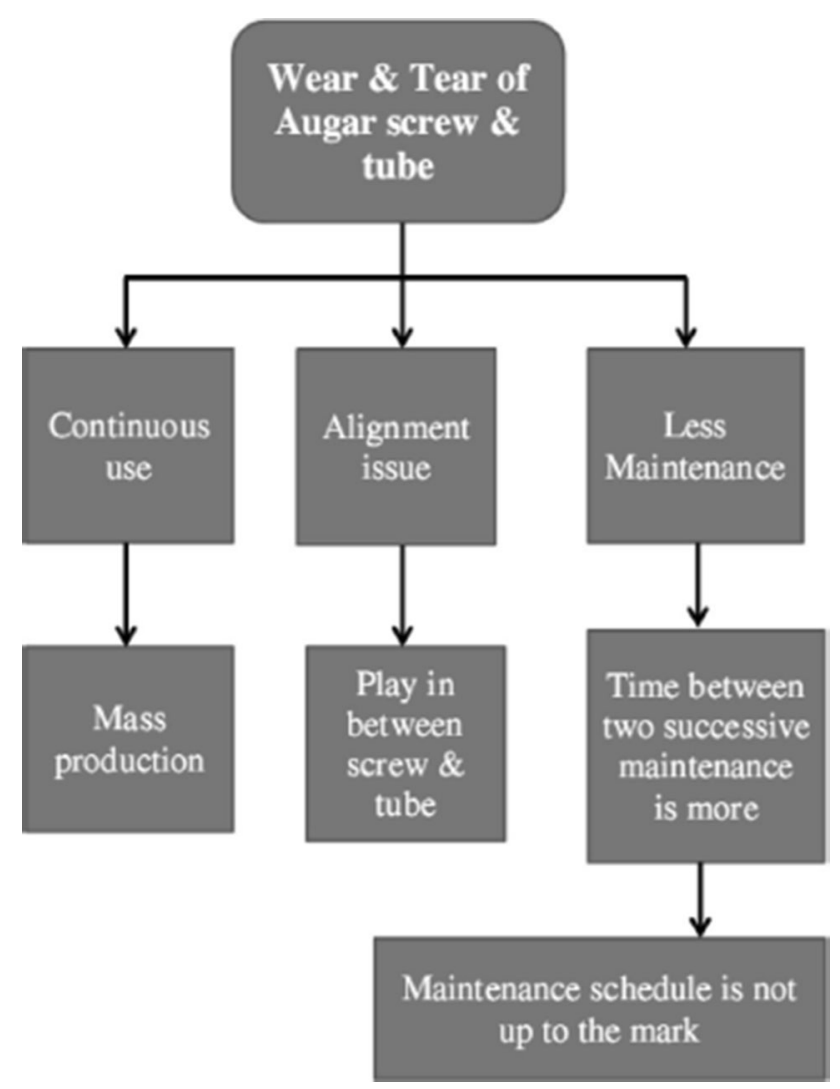

Fig. 7 Why-why analysis of wear and tear of augar screw and tube assembly

- Planning for changeover of product should be such that it takes minimum time to set the machine for new product and maximize the machine availability time.

- Maintenance should be planned during product changeover.

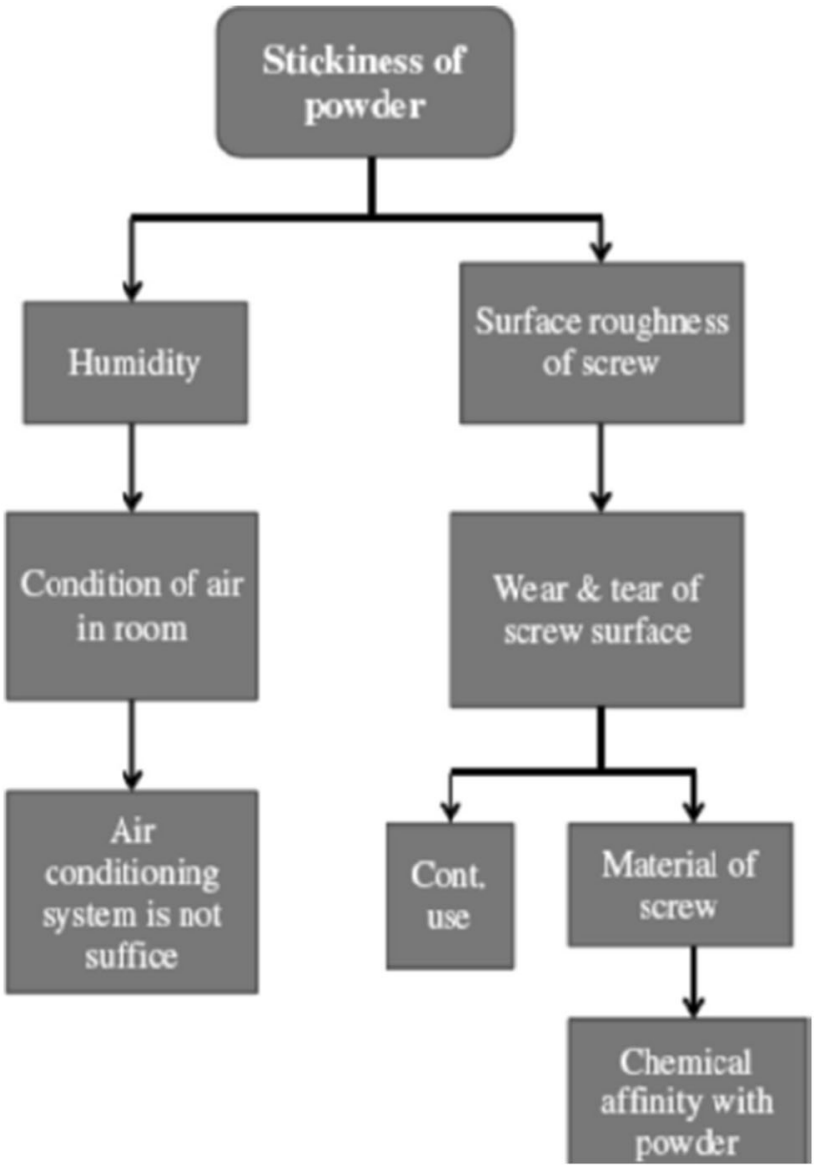

Fig. 8 Why-why analysis of stickiness of powder

Control phase

Depending up on type of the problem and operating system of the concern, the following control measures were suggested: 


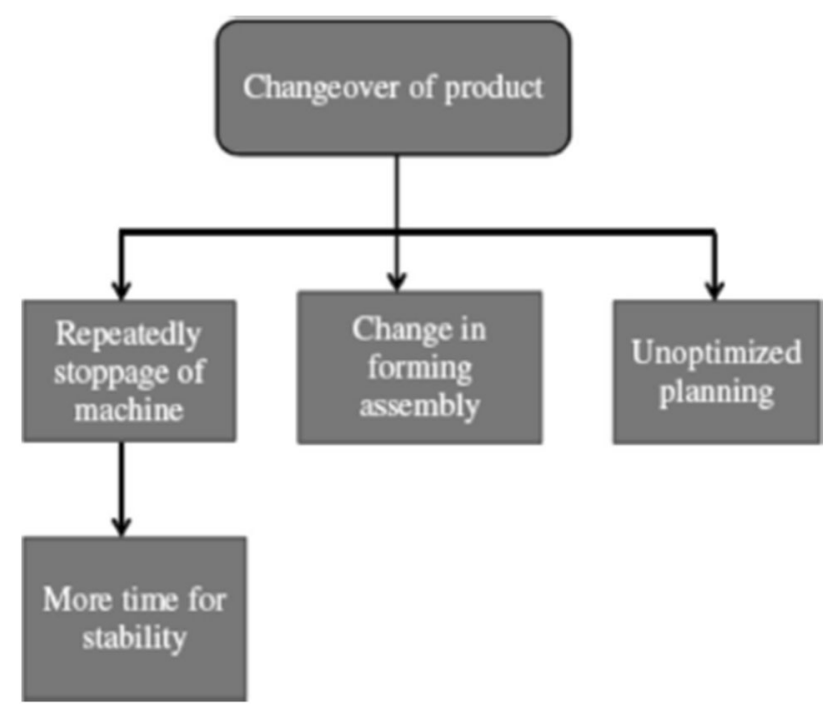

Fig. 9 Why-why analysis of changeover of product

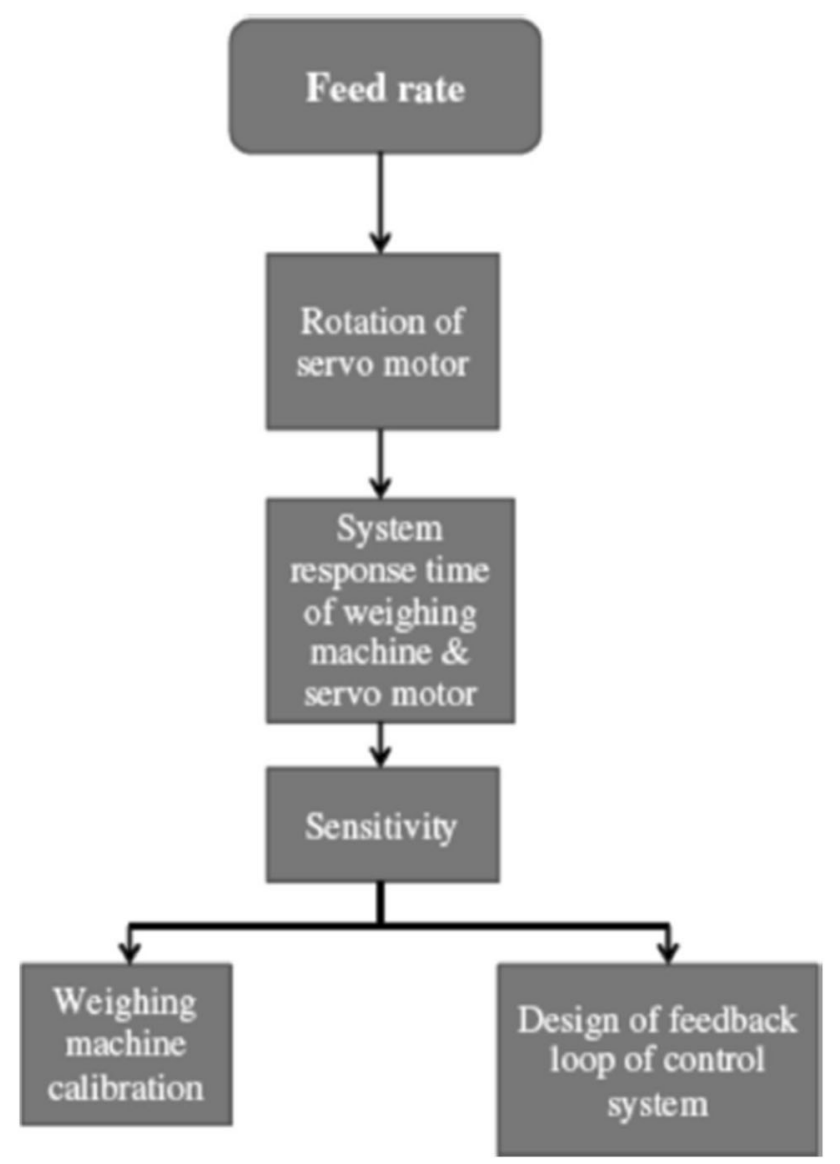

Fig. 10 Why-why analysis of feed rate

Periodic review of the different measures recommended in improve phase.

$\checkmark$ Application statistical quality control charts, like $\mathrm{X}$-bar and S-chart to check the consistency of the process maintaining targeted sigma level.

\section{Managerial implications}

India is one of the largest food producers in the world. The total food production in India is likely to double in next decade creating huge potential for technological innovations and quality improvements. The opportunities of strategic investment will be ample in the areas like dairy and food processing, milk and milk products, specialty processing, fruits and vegetables, beverages and soft drinks, fisheries, food and grains, packaging, cold storages etc.

Most Six Sigma projects are geared toward improving business process, innovation performance, and technical performance in such a way that it may help in satisfying customer needs and expectations. The focus of the projects selected for deploying Six Sigma is to meet the stated goals within budget and time constraints (Wu et al. 2012). To meet this objective of breakthrough improvement in the business process organizations are many times underestimating the supplementary processes as candidate for Six Sigma implementation initiative. The process selected here of packaging the milk powder, though appears supporting, demonstrated a large potential for improvement leading to bottom-line gain of considerable magnitude. This case study has opened up a parallel way of analyzing and selecting supplementary processes, especially in foodprocessing sectors, to take up the same as lucrative Six Sigma project.

\section{Concluding remarks}

The basic objective of this study was to implement Six Sigma improvement methodology at one of the critical units of food-processing industry and illustrate the benefits drawn out of the same. The DMAIC methodology was applied to one of the chronic problems having considerable impact on the quality and productivity of the unit in question. Based on the rigorous analysis of various root causes several improvement measures were suggested. The implementation of DMAIC methodology resulted in understanding the problems from all aspects, qualitatively as well as quantitatively, and laying out the improvements through effective analysis of the roots of the problem. The problem of variations in the weight of $1 \mathrm{~kg}$ milk powder pouch was addressed satisfactorily and the rejection rate was brought down to $50 \%$. The financial benefits projected as a result of this pilot Six Sigma project was to the tune of $8,00,000$ INR per annum. This project was taken up on one the many different sizes and types of milk powder packaging undergoing the same process. The potential of improvement thus appears significant if the same improvement methodology can be applied to packaging 
process of other varieties. The cumulative savings can be of very large magnitude justifying the application of Six Sigma improvement methodology across the unit on different packaging process.

Acknowledgments The authors duly acknowledge the research works, project reports, books, website, etc., whose reference were taken in forming this research paper. All works are appropriately cited and referred at the reference section of this paper. The authors are also thankful to anonymous reviewers for their constructive remarks in making this paper more effective.

Open Access This article is distributed under the terms of the Creative Commons Attribution License which permits any use, distribution, and reproduction in any medium, provided the original author(s) and the source are credited.

\section{References}

Antony J, Desai DA (2009) Assessing the status of Six Sigma implementation in the Indian industry: results from an exploratory empirical study. Manag Res News 32(5):413-423

Antony J, Kumar M, Mandu C (2005) Six Sigma in small and medium sized UK manufacturing enterprises: some empirical observations. Int J Qual Reliabil Manag 22(8):860-874

APO (2013) Asian Productivity Organization (APO) News, APO, Japan, January-February 2013, vol 43(1)

Bilgen B, Şen M (2012) Project selection through fuzzy analytic hierarchy process and a case study on Six Sigma implementation in an automotive industry. Prod Plan Control Manag Oper 23(1):2-25. doi:10.1080/09537287.2010.537286

Chakrabortty RK, Biswas TK, Ahmed I (2013) Reducing process variability by using DMAIC model: a case study in Bangladesh. Int J Qual Res 7(1):127-140

Cooper DR, Schinddler PS (2005) Business research methods. Tata McGraw-Hill, New Delhi

Cutler RT (2007) Food manufacturing and Six Sigma. Technol Manag Decis Mak 2:20-22

Dedhia NS (2005) Six Sigma basics. Total Qual Manag 16(5): $567-574$

Deloitte (2009) Enhancing firm level competitiveness Indian food and agro processing industry Strategies and road map development, a study conducted by Deloitte Touche Tohmatsu India Private Limited. Member of Deloitte Touche Tohmatsu for National Manufacturing Competitiveness Council, Government of India

Desai DA, Patel MB (2009) Impact of Six Sigma in a developing economy: analysis on benefits drawn by Indian industries. J Ind Eng Manag 2(3):517-538

Desai DA, Patel MB (2010) Six Sigma implementation barriers in Indian industries-survey results and case studies. Int $\mathrm{J}$ Bus Excell 3(2):142-162

Eckes G (2001) The Six Sigma revolution: how general electric and others turned process into profits. Wiley, New York

Harry MJ (1998) Six Sigma: a breakthrough strategy for profitability. Qual Prog 31:60-64

Hung HC, Sung MH (2011) Applying six sigma to manufacturing processes in the food industry to reduce quality cost. Sci Res Essays 6(3):580-591

Jonathan C Director of Business Development, TBM Consulting Group-Mexico, White paper on "small improvements in rawmaterial yield make big improvements to bottom-line profitability-applying the DMAIC process to continuous process manufacturing in the food and beverage industry", TBM Consulting
Group, Inc 4400 Ben Franklin Blvd. Durham, NC 27704 800.438.5535. http://www.tbmcg.com

Kovach T, Cho R (2011) Better processes make GOOD EATS: food industry can benefit from lean Six Sigma principles. Ind Eng IE 43(1):36-40

Wu KS, Yang LR, Chiang IC (2012) Leadership and Six Sigma project success: the role of member cohesiveness and resource management. Prod Plan Control Manag Oper 23(9):707-717. doi:10.1080/09537287.2011.586650

Lucas JM (2002) The essential Six Sigma. Qual Prog 35:27-31

Nabhani F, Shokri A (2009) Reducing the delivery lead time in a food distribution SME through the implementation of Six Sigma methodology. J Manuf Technol Manag 20(7):957-974

Nabhani F, Shokri A (2007) Application of Six Sigma in a food distribution SME to improve supply chain management. In: Proceedings of the World Congress on Engineering 2007 Vol II WCE 2007, July 2-4, 2007, London, UK

NPC (2012) Annual Report 2011-2012. National Productivity Council, New Delhi

Park SH (2002) Six Sigma for productivity improvement: Korean business corporations. Productivity 43(2):173-183

Pyzdek T (1999) The Six Sigma revolution. Quality America, Tucson

Shahin A (2008) Design for Six Sigma (DFSS): lessons learned from world-class companies. Int J Six Sigma Compet Adv 4(1):48-59

Sharma G, Rao PS (2013) Process capability improvement of an engine connecting rod machining process. J Ind Eng Int 9:37

Simon JL (1969) Basic research methods in Social Science-the art of empirical investigation. Random House, New York

Six Sigma Online (2009) Lean six sigma-practical applications in fast food. Retrieved from http://www.sixsigmaonline.org/sixsigma-training-certificationinformation/articles/lean-six-sigmapractical-applications-in-fast-food-.html

Snee RD (2004) Six Sigma: the evolution of 100 years of business improvement methodology. Int J Six Sigma Compet Adv $1(1): 4-20$

Tang LC, Goh TN, Lam SW, Zhang CW (2007) Fortification of Six Sigma: expanding the DMAIC toolset. Qual Reliabil Eng Int 23:3-18

Tomkins R (1997) GE beats expected $13 \%$ rise. Financ Times 10:22

Tylutki TP, Fox DG (2002) Mooooving toward Six Sigma—a quality management program helps one farm manage its feed costs. Qual Prog 35:34-41

Voelkel JG (2002) Something's missing —an education in statistical methods will make employees more valuable to Six Sigma corporations. Qual Prog 98-101

Wright JN, Basu R (2008) Project management and Six Sigma: obtaining a fit. Int J Six Sigma Compet Adv 4(1):81-94

Yin RK (2003) Case study research: design and method, 3rd edn. Sage, CA

Zhang Q, Irfan M, Khattak MAO, Zhu X, Hassan M (2012) Lean Six Sigma: a literature review. Interdiscip J Contemp Res Bus 3(10):599-605

Zhen Y (2011) Food safety and Lean Six Sigma Model, thesis for Master of Science in the Department of Safety Science University of Central Missouri, October 2011

Darshak A. Desai is an Academician with rich industrial background in design, operations, projects, and marketing. Currently, he is a Professor and Head of the Department of Mechanical Engineering, G.H. Patel College of Engineering and Technology (GCET), Vallabh Vidyanagar, Gujarat, India. Graduate in Production Engineering, he earned his post-graduation in Industrial Engineering. His Doctoral study is in the field of Six Sigma. His area of interest is quality and operations management. He has presented and published 28 papers at national and international levels. He has published, as a co-author, 
seven books in regional language and English. He is an Invited Reviewer in about ten international journals.

Parth Kotadiya graduated in Mechanical Engineering from G.H. Patel College of Engineering and Technology (GCET), Vallabh Vidyanagar, Gujarat, India. They were the part of Six Sigma team for the project in question.

Nikheel Makwana graduated in Mechanical Engineering from G.H. Patel College of Engineering and Technology (GCET), Vallabh
Vidyanagar, Gujarat, India. They were the part of Six Sigma team for the project in question.

Sonalinkumar graduated in Mechanical Engineering from G.H. Patel College of Engineering and Technology (GCET), Vallabh Vidyanagar, Gujarat, India. They were the part of Six Sigma team for the project in question. 